\title{
Dissolution and formation of nuclear materials in molten media*
}

\author{
T. Ogawa ${ }^{\dagger}$ and K. Minato \\ Japan Atomic Energy Research Institute, Tokai-mura, Naka-gun, Ibaraki-ken, \\ 319-1195 Japan
}

\begin{abstract}
As innovative means to recover actinides from irradiated fuels, pyrochemical processes are proposed. In the Japan Atomic Energy Research Institute (JAERI), the feasibility of applying molten-salts processes to nitride fuels containing transuranium elements for transmutation is investigated. In the course of study, experiments and analyses have been made on the high-temperature chemistry of $\mathrm{M}-\mathrm{N}-\mathrm{Cl}$ systems, the effects of oxygen impurities, and the implications of the divalent state along with the normal trivalent state of lanthanides and actinides. Thermodynamic calculation and the electrochemical measurements are compared in a few aspects of dissolution and precipitation of nuclear materials in molten halides.
\end{abstract}

\section{INTRODUCTION}

Partitioning and transmutation of long-lived radioactive wastes, particularly transuranium elements (TRUs), are important research subjects for continuing utilization of nuclear energy. The TRUs (neptunium, plutonium, americium, and curium) may be charged into a reactor or an accelerator-driven system as either metal, oxide, or nitride target, and converted to shorter-lived nuclides. Technical innovation is required in the separation of actinides from fission products and the refabrication into the target form, since these TRUs are radiologically toxic and characterized by larger $\alpha$-decay heat and neutron emissions than the normal nuclear fuel based on uranium.

Although the separation of actinides and fission products has been made by aqueous chemistry on industrial scales, pyrochemical techniques are recently studied as viable routes to treat the burn-up TRU targets. The burn-up targets will be dissolved and refabricated in molten salts and/or alloys. The molten-salts electrolysis has been extensively studied for treating uranium-based metallic fuels in the United States. Similar technologies may be adapted to also recover fissile materials from ceramic fuels.

Interest in pyrochemical separation is also due to the potential improvement it offers to the economy of nuclear energy. It has a potential to attain economical competitiveness even with a modest-scale plant. This is an advantage over state-of-the-art aqueous processes, with which a huge centralized plant has to be built to be economically viable. In this way, pyroprocessing may give greater flexibility to a nation's nuclear energy strategy. Besides, this modular-type approach would enhance the evolution of technology, compared with the huge-plant approach where the next plant will not be sold for another 20-30 years.

The behavior of metal nitrides in $\mathrm{LiCl}-\mathrm{KCl}$ eutectic melts is being studied in the Japan Atomic Energy Research Institute (JAERI). The dissolution can be achieved by reacting with an oxidizing agent such as $\mathrm{CdCl}_{2}$ or by applying certain potential to the nitrides (anodic dissolution). There are a few fundamental questions:

- behavior of nitrogen and impurity oxygen, the latter of which is an inevitable ingredient in the industrial process

\footnotetext{
*Lecture presented at the $9^{\text {th }}$ IUPAC International Symposium on Solubility Phenomena $\left(9^{\text {th }}\right.$ ISSP), Hammamet, Tunisia, 25-28 July 2000. Other presentations are published in this issue, pp. 761-844.

${ }^{\dagger}$ Corresponding author
} 
- $\quad$ electrochemical inhomogeneity between the cathode and anode in the electrolysis

- the fact that actinides and lanthanides may take several ionic states in the electrochemically inhomogeneous environment

Regarding the last point, the stability of divalent state has an observable effect in the treatment of some lanthanides and americium. The above questions are not limited to the nitride/pyrochemical separation, but they should also pertain to other related systems.

\section{EXPERIENCE IN PROCESS DEVELOPMENT}

Nitride chemistry has been defined with a reasonable certainty only for UN and PuN. The ternary systems of $\mathrm{U}-\mathrm{N}-\mathrm{Cl}$ and $\mathrm{U}-\mathrm{N}-\mathrm{F}$ are discussed in ref. 1. During anodic polarization of $\mathrm{UN}$ in $\mathrm{LiCl}-\mathrm{KCl}$ eutectic melt, $\mathrm{UN}$ is dissolved as chloride, but a ternary compound $\mathrm{UNCl}$ is also formed. The exact condition of the $\mathrm{UNCl}$ formation and decomposition has yet to be formulated. The experimental evidences to date do not indicate the interference of nitride chloride during the molten-salts electrolysis of $\mathrm{NpN}$ and PuN [2].

Recently, Franklin et al. [3] studied the Dy-N-Cl system in $\mathrm{LiCl}-\mathrm{KCl}$ eutectic melt. Dysprosium is regarded as a surrogate of the transuranium element americium. The interference due to the possible formation of $\mathrm{DyCl}_{2}$ has been noticed. When one immersed a solid metal Dy in $\mathrm{LiCl}-\mathrm{KCl}-\mathrm{DyCl}_{3}$, the metal reacts with $\mathrm{DyCl}_{3}$ to form $\mathrm{DyCl}_{2}$. The $\mathrm{DyCl}_{2}$, which may be either dissolved or segregated as fine particles, was dispersed in the bulk of molten salts, and appeared to disproportionate into Dy and $\mathrm{DyCl}_{3}$ at the other parts. A similar interference has also been suspected in the electrolysis of DyN. There was a significant difference in the behavior of $\mathrm{DyN}$ between the simple oxidation by $\mathrm{CdCl}_{2}$ and the anodic dissolution. When DyN was oxidized by $\mathrm{LiCl}-\mathrm{KCl}-\mathrm{CdCl}_{2}$ mixtures, nitrogen evolved as $\mathrm{N}_{2}$ to nearly $100 \%$ [4]. However, at the anodic dissolution of $\mathrm{DyN}$ in $\mathrm{LiCl}-\mathrm{KCl}$ eutectic melt with a solid metal cathode, DyN became passivated to an extent and nitrogen evolution was significantly suppressed. This illustrates the importance of studying the $\mathrm{M}(\mathrm{III}) / \mathrm{M}(\mathrm{II}) / \mathrm{M}$ equilibria in molten salts.

The nitride fuels may be fabricated either from metals or oxides. Since the actinides from commercial reactor fuel cycles may be supplied as oxides, the processes to convert the oxides to nitrides have been investigated. We have studied the carbothermic reduction of the actinide oxides in nitrogencontaining atmosphere. Both the experiments and analyses indicate the increasing difficulty of removing oxygen impurities with increasing atomic number. This oxygen impurity from the fuel fabrication would be carried into the molten-salts processes after the irradiation.

The behavior of oxygen and nitrogen is also of concern in the other pyrochemical processes. In the metallic fuel concepts where the irradiated metal fuel is treated by the molten-salts electrorefining [5], oxygen is a common impurity. In the processes developed in RIAR, Russia, the oxides are directly dissolved and precipitated in the molten chlorides [6]. Nitrogen chemistry is also important in a process using lithium as an agent to reduce oxides into metals in molten $\mathrm{LiCl}$ [7], where $\mathrm{Li}$ tends to pick up nitrogen impurities in the inert-gas atmosphere.

A few pertinent aspects related to solubility phenomena in molten salts are discussed below.

\section{THERMODYNAMIC DATABASE AND ELECTROCHEMISTRY}

\section{Cyclic voltammetry}

The electrochemical processes should not be reduced to the equilibrium consideration. The ions would have to pass several intermediate stages near the electrodes. Besides, there should be factors specific to the geometry of each electrochemical setting. Nevertheless, thermodynamic analysis would give a useful framework for analyzing the electrochemical processes in combination with various electrochemical criteria. 
The free energy of formation and activity coefficient $(\gamma)$ of the super-cooled liquid chlorides appear to give a good framework to predict the apparent redox behavior in the molten salts. For example, the free energy of formation of super-cooled liquid $\mathrm{DyCl}_{3}$ is estimated as

$$
-960.68+0.2148 \mathrm{~T}(\mathrm{~kJ} / \mathrm{mol}) \text {. }
$$

In ref. 8, the activity coefficients of the super-cooled liquid trichlorides of lanthanides and actinides in $\mathrm{LiCl}-\mathrm{KCl}$ eutectic melt were fitted by

$$
\mathrm{RT} \ln \gamma=-438.1+4004 r
$$

where $r$ is the Shannon's ionic radius $(\mathrm{CN}=6)$ [9] in $\mathrm{nm}$. This gives the equilibrium potential of $\mathrm{Dy} / \mathrm{Dy}^{3+}(0.00035$ in molar fraction) referring to $\mathrm{Ag} / \mathrm{AgCl}(10 \mathrm{~mol} \%)$ to be $-2.12 \mathrm{~V}$ at $773 \mathrm{~K}$. The recent data give $-2.1[3]--2.2 \mathrm{~V}[10]$.

Cyclic voltammetry has been used to understand the electrochemical behavior of metal ions in molten salts. The cyclic voltammogram of trivalent actinides and lanthanides to and from the respective metal appears to be characterized by a strong asymmetry between the cathodic and anodic curves. In addition, at lower concentrations, a noticeable cathodic prepeak and an associated anodic peak have been observed, which have been explained by theformation of insoluble low-valent species adsorbed on the electrode [10-12]. Serrano and Taxil [10], who combined modern techniques, concluded for U(III) in $\mathrm{NaCl}-\mathrm{KCl}$ equimolar molten salts that the adsorption of $\mathrm{U}(\mathrm{I})$ competes with a single-step reversible reduction:

$$
\mathrm{U}^{3+}+3 \mathrm{e}^{-}=\mathrm{U}
$$

The latter type of single-step reduction has been confirmed also for $\mathrm{Pu}^{3+}$ in $\mathrm{LiCl}-\mathrm{KCl}$ eutectic melt [13].

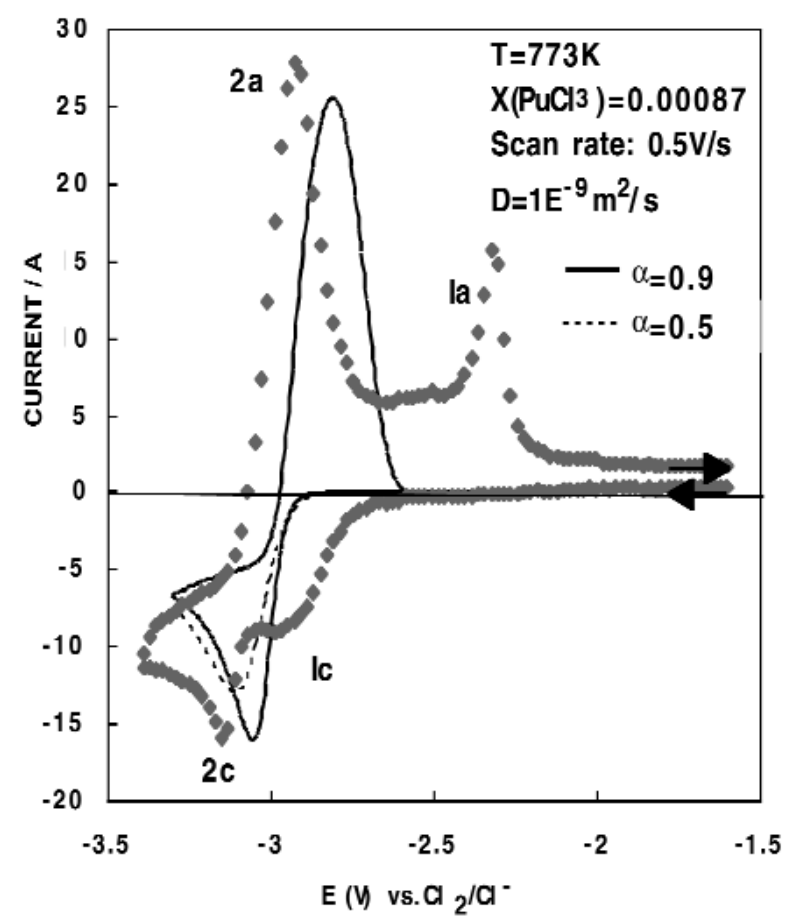

Fig. 1 Experimental cyclic voltammogram [12] and results of numerical analysis (solid and dashed lines) of $\mathrm{Pu}^{3+}$ in $\mathrm{LiCl}-\mathrm{KCl}$ eutectic at $773 \mathrm{~K}$.

(C) 2001 IUPAC, Pure and Applied Chemistry 73, 799-806 
Figure 1 compares the experimental cyclic voltammogram on $\mathrm{Pu}^{3+}$ in $\mathrm{LiCl}-\mathrm{KCl}$ eutectic at $773 \mathrm{~K}$ by Shirai et al. [12] with results of a numerical analysis. In its simplest form, the numerical analysis combines the ionic diffusion in the vicinity of the electrode with an electron transfer process which is expressed by a Butler-Volmer-type equation:

$$
i / n \mathrm{FA}=\mathrm{kC}_{\mathrm{ox}} \exp \left[-(\alpha n \mathrm{~F} / \mathrm{RT})\left(\mathrm{E}-\mathrm{E}_{\mathrm{o}}{ }^{\prime}\right)\right]-\mathrm{kC}_{\mathrm{red}} \exp \left[\{(1-\alpha) n \mathrm{~F} / \mathrm{RT}\}\left(\mathrm{E}_{-}-\mathrm{E}_{\mathrm{o}}{ }^{\prime}\right)\right]
$$

where $i$ is the current, $n$ is the number of transferred electrons, $\alpha$ is the transfer coefficient, $\mathrm{k}$ is the heterogeneous rate constant, $\mathrm{F}$ is the Faraday constant, $\mathrm{E}$ is the electrode potential, and $\mathrm{A}$ is the effective surface area. The $\mathrm{E}_{\mathrm{o}}{ }^{\prime}$ is given by

$$
\mathrm{E}_{\mathrm{o}}{ }^{\prime}=\left[\Delta \mathrm{G}_{\mathrm{f}}^{\mathrm{o}}\left(\mathrm{MCl}_{3}\right)+\mathrm{RT} \ln \gamma\left(\mathrm{MCl}_{3}\right)+\mathrm{RT} \ln \mathrm{X}_{\mathrm{o}}\left(\mathrm{MCl}_{3}\right)\right] / 3 \mathrm{~F}
$$

where $\gamma$ is the activity coefficient and $X_{o}$ is the molar fraction at the interface at the given instance. The numerical procedure is described by Gosser [14].

In the numerical analysis, the existence of prepeaks (1c and 1a) is not taken into account. The position of experimental major peaks ( $2 \mathrm{c}$ and $2 \mathrm{a}$ ) are at more negative potential (about $-0.08 \mathrm{~V}$ ) than the calculated ones. A part of the discrepancy is explained by the depletion of effective $\mathrm{PuCl}_{3}$ concentration due to the prepeak 1a. The $\gamma\left(\mathrm{PuCl}_{3}\right)$ by eq 2 can reproduce two sets of emf measurements $[15,16]$, but the agreement is not ideal when compared with data of chronopotentiometry [13] and cyclic voltammetry. Apart from this uncertainty, the numerical analysis reasonably reproduces the experimental peaks ( $2 \mathrm{c}$ and $2 \mathrm{a}$ ) with the following assumptions:

- $\quad$ The transfer coefficient, $\alpha$, significantly deviates from 0.5 .

- $\quad \mathrm{E}_{\mathrm{o}}{ }^{\prime}$ of the anodic process cannot be defined by eq 5; the anodic peak position with reference to the cathodic one can be reproduced by setting $\mathrm{X}\left(\mathrm{PuCl}_{3}\right) \sim 0.02$, which is significantly higher than the concentration in the bulk salt $\left[\mathrm{X}\left(\mathrm{PuCl}_{3}\right)=0.00087\right]$.

- Diffusion coefficient of $\mathrm{Pu}^{3+}$ is $1 \times 10^{-9} \mathrm{~m}^{2} / \mathrm{s}$ at $773 \mathrm{~K}$ [13].

It is hard to determine $\alpha$ from the cyclic voltammogram, but the sharply peaked shape of $2 \mathrm{c}$ and a relatively large half-width of $2 \mathrm{a}$ are better explained by $\alpha$ larger than 0.5 . One would like to relate $\mathrm{X}\left(\mathrm{PuCl}_{3}\right) \sim 0.02$ to the solubility limit in the molten salts, but the latter would be much larger than 0.02 , considering the existing thermodynamic data of the $\mathrm{KCl}-\mathrm{MCl}_{3}$ compounds [17-19]. The experience in JAERI also supports that it is larger than $25 \mathrm{wt} \%$ [29]. Since the geometrical factors are totally neglected in the numerical analysis, a more detailed comparison would be meaningless. A clearer understanding of these electrode processes is vital in the simulation of pyroprocesses in general. Further investigation by modern electrochemical techniques and numerical analyses with refined thermodynamic data would be helpful.

\section{Solubility of oxide-chlorides}

Uranium oxide has a limited solubility in the chloride melts. Harder et al. [20] have studied the molten $\mathrm{UCl}_{4}-\mathrm{NaCl}$ system. They found that the oxide solubility in the molten salts increases with $\mathrm{UCl}_{4}$ concentration. This effect cannot be explained by the solubility product: $\mathrm{L}=\left(\mathrm{U}^{4+}\right)\left(\mathrm{O}^{2-}\right)^{2}$.

The solubility of $\mathrm{UO}_{2}$ in $\mathrm{LiCl}-\mathrm{KCl}$ eutectic melt has been determined by Molina [21] to be a mole fraction of $3.7 \times 10^{-5}$ at $723 \mathrm{~K}$. In view of the above observation on $\mathrm{UCl}_{4}-\mathrm{NaCl}$ molten salts, it is hard to assume that the dissolved $\mathrm{UO}_{2}$ is dissociated into $\mathrm{U}^{4+}$ and $\mathrm{O}^{2-}$. Chiotti et al. [22] modeled the solubility of $\mathrm{UO}_{2}$ in $\mathrm{LiCl}-\mathrm{KCl}$ eutectic melt by assuming that the dissolved species is $\mathrm{UOCl}_{2}$. The reaction of $\mathrm{ThCl}_{4}$ with $\mathrm{UO}_{2}$ in $\mathrm{LiCl}-\mathrm{KCl}$ eutectic melt was successfully explained by the model.

The oxide behavior has been discussed by using a modified Pourbaix diagram $\left(\mathrm{E}-p\left(\mathrm{O}^{2-}\right)\right.$ diagram). The $p\left(\mathrm{O}^{2-}\right)$ is given by $\log _{10}\left[\mathrm{O}^{2-}\right]$ where $\mathrm{O}^{2-}$ is the concentration of "free" oxide ion. Solubility products, $\mathrm{L}=\left(\mathrm{M}^{4+}\right)\left(\mathrm{O}^{2-}\right)^{2}$, have been determined for actinides in molten chlorides [23] by a potentio- 
metric titration with $\mathrm{Li}_{2} \mathrm{O}$ or $\mathrm{Na}_{2} \mathrm{CO}_{3}$. The potential of an oxide-ion indicator electrode against a reference electrode is read during titration, and converted to $p\left(\mathrm{O}^{2-}\right)$ with a calibration curve. The techniques of potentiometric titration of molten halides or halogenides are discussed in wider perspectives in refs $[24,25]$.

If a metal oxide has a limited solubility in molten halides, the interpretation of the potentiometric titration would not be straightforward. Figure 2 shows a result of thermodynamic prediction, where the solubility of uranium oxide is modeled by the formation of hypothetical $\mathrm{UOCl}_{2}(\mathrm{LiCl})_{2}$ dissolved in the molten salts. Similar results are obtained by simply assuming $\mathrm{UOCl}_{2}$ as the dissolved species, instead; the present formulation would make it somewhat easier to view the system behavior as that of $\mathrm{UCl}_{4}-\mathrm{Li}_{2} \mathrm{O}$ pseudo binary:

$$
\begin{aligned}
& {\left[\mathrm{UCl}_{4}\right]+\left[\mathrm{Li}_{2} \mathrm{O}\right]=\left[\mathrm{UOCl}_{2}(\mathrm{LiCl})_{2}\right]} \\
& {\left[\mathrm{UOCl}_{2}\left(\mathrm{LiCl}_{2}\right]+\left[\mathrm{Li}_{2} \mathrm{O}\right]=<\mathrm{UO}_{2}>+4[\mathrm{LiCl}]\right.}
\end{aligned}
$$

Here the sign [ ] denotes a component in the liquid phase; $<>$ denotes a solid phase.

The activity coefficient of $\mathrm{Li}_{2} \mathrm{O}$ in $\mathrm{LiCl}-\mathrm{KCl}$ eutectic has been derived from the data by Kanzaki and Takahashi [26,27]. A simple sum of the free energy of formation of $\left\langle\mathrm{UOCl}_{2}>\right.$ and $2<\mathrm{Li}_{2} \mathrm{O}>$ gives $-1571.5 \mathrm{~kJ} / \mathrm{mol}$ at $723 \mathrm{~K}$; a slight modification to $\Delta \mathrm{G}_{\mathrm{f}}^{\mathrm{o}}\left[\right.$ liquid $\left.\mathrm{UOCl}_{2}(\mathrm{LiCl})_{2}\right]=-1575 \mathrm{~kJ} / \mathrm{mol}$ can explain the solubility data by Molina [21]. The chain line in the figure corresponds to the potential of oxide-ion indicator as a function of oxide-ion concentration. Therefore, the chain line is regarded as a calibration curve used in the experiments. The solubility limit of oxide can be defined only by a shallow knee at about $\log _{10}\left[\mathrm{Xo}\left(\mathrm{Li}_{2} \mathrm{O}\right)\right] \sim-5$, where $\mathrm{Xo}$ is the added amount. While $\mathrm{UO}_{2}$ is precipitating, the potential remains nearly constant. Eventually at the termination of $\mathrm{UO}_{2}$ precipitation and the sudden rise in the $\left[\mathrm{Li}_{2} \mathrm{O}\right]$ concentration, a large potential gap appears. After this point, the slope of the titration curve converges to that of the chain line. If one derives the solubility product, $\mathrm{L}=\left(\mathrm{M}^{4+}\right)\left(\mathrm{O}^{2-}\right)^{2}$, by fitting the last part (around the equivalent point $\left[\mathrm{Li}_{2} \mathrm{O}\right] /\left[\mathrm{UCl}_{4}\right]=2$ ) of the titration curve, the result might fail to give the correct picture on the behavior of the whole system.



Fig. 2 Predicted potentiometric titration behavior of $\mathrm{U}^{4+}$ in $\mathrm{LiCl}-\mathrm{KCl}$ eutectic at $723 \mathrm{~K}$. 


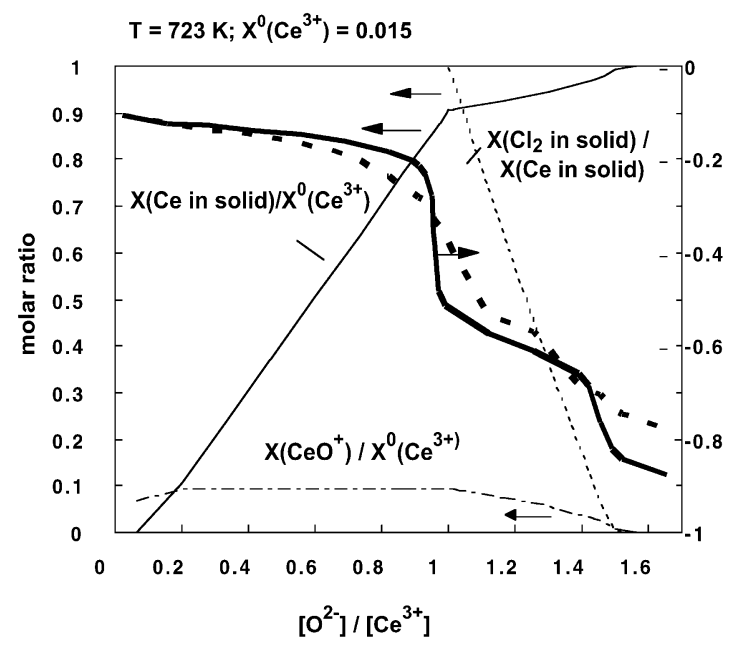

Fig. 3 Predicted potentiometric titration behavior of $\mathrm{Ce}^{3+}$ in $\mathrm{LiCl}-\mathrm{KCl}$ eutectic at $723 \mathrm{~K}$. The potential of the experimental curve by Combes et al. [32] is shifted to give approximate coincidence with the prediction at $\left[\mathrm{O}^{2-}\right] /\left[\mathrm{Ce}^{3+}\right] \sim 0.1$

Figure 3 gives another example where the behavior of cerium(III) oxide in $\mathrm{LiCl}-\mathrm{KCl}$ eutectic melt is predicted. It is assumed that cerium(III) oxide dissolves as $[\mathrm{CeOCl}] . \Delta \mathrm{G}_{\mathrm{f}}^{\mathrm{O}}(\mathrm{CeOCl})$ is unknown; it is assumed to be close to that of $\mathrm{NdOCl},-864.8 \mathrm{~kJ} / \mathrm{mol}$ at $723 \mathrm{~K}$. In the liquid phase, the activity coefficient referring to the solid is assumed to be $\mathrm{RT} \ln \gamma(\mathrm{CeOCl})=30 \mathrm{~kJ} / \mathrm{mol}$ to have a qualitative agreement with the experimental data as discussed below. The solid phase is assumed to be the ideal solution of $<\mathrm{Ce}_{2} \mathrm{O}_{3}>$ and $2<\mathrm{CeOCl}>$. Again, the ordinate corresponds to the potential of the oxide-ion indicator, although it is shifted from that of Fig. 2 by the free-energy term of $\mathrm{LiCl}$ in the melt. The prediction (bold solid line) reproduces the trend of the experimental results (bold dashed line) by Combes et al. [28] on cerium(III) oxide in $\mathrm{NaCl}-\mathrm{KCl}$ at $1000 \mathrm{~K}$. Combes et al. assigned the first bend at $\left[\mathrm{O}^{2-}\right] /\left[\mathrm{Ce}^{3+}\right]=1$ to the formation of $\left[\mathrm{CeO}^{+}\right]$, and the second at $\left.\left[\mathrm{O}^{2-}\right] / \mathrm{Ce}^{3+}\right]=1.5$ to that of $<\mathrm{Ce}_{2} \mathrm{O}_{3}>$. The calculation suggests that $\left[\mathrm{CeO}^{+}\right]$is formed at very low oxide-ion concentrations; the moderate change in the potential before the first bend represents the gradual precipitation of $\langle\mathrm{CeOCl}\rangle$; the first sharp bend is marked by the beginning of precipitation of $\left\langle\mathrm{Ce}_{2} \mathrm{O}_{3}>\right.$; the second bend as the complete conversion of remaining $\left[\mathrm{CeO}^{+}\right]$into solids, and then, the completion of conversion of mixed oxides to $\left\langle\mathrm{Ce}_{2} \mathrm{O}_{3}>\right.$. Since the thermodynamic data used here are very tentative and the supporting molten salts systems are different, the results by Combes et al. cannot be directly compared with the present prediction. However, further study would be warranted to reach more detailed understanding of the oxide bahavior in the molten salts. For instance, the combination of electrochemical and spectrometric techniques should help clarify the reactions involved in the halide melts containing oxide ion.

Recently, Higashi and Minato have applied a high-temperature UV-vis spectrophotometry to study the behavior of $\mathrm{Nd}-\mathrm{O}-\mathrm{Cl}$ system in $\mathrm{LiCl}-\mathrm{KCl}$ eutectic. The depletion of $\mathrm{Nd}^{3+}$ was measured as a function of added amount of $\mathrm{Li}_{2} \mathrm{O}$. The results indicated:

- the precipitation began from a very low $\left[\mathrm{O}^{2-}\right]$ and

- it significantly increased at concentrations $\left.\left[\mathrm{O}^{2-}\right] / \mathrm{Nd}^{3+}\right]>1.0$ and terminated at $\left.\left[\mathrm{O}^{2-}\right] / \mathrm{Nd}^{3+}\right]=1.5$.

This behavior could be explained by assuming that $\mathrm{NdOCl}$ and $\mathrm{Nd}_{2} \mathrm{O}_{3}$ precipitates separately without forming solid solutions in $\mathrm{LiCl}-\mathrm{KCl}$ eutectic at $723 \mathrm{~K}$. 


\section{ACKNOWLEDGMENTS}

The authors wish to thank Dr. K. Franklin, Dr. O. Shiarai, and Mr. T. Higashi for discussions and comments on the recent experimental data.

\section{REFERENCES}

1. T. Ogawa, F. Kobayashi, T. Sato, R. G. Haire. J. Alloys Comp. 271-273, 347-354 (1998).

2. Y. Arai, T. Iwai, K. Nakajima, O. Shirai, Y. Suzuki. "Experimental research on nitride fuel cycle in JAERI", Proceedings of the International Conference on Future Nuclear Systems Global'99, 29 August-3 September 1999, Jackson Hole, Wyoming.

3. K. Franklin, F. Kobayashi, M. Akabori, M. Takano, A. Itoh, T. Ogawa, "A study on the electrode potential of dysprosium metal and dysprosium nitride in $\mathrm{LiCl}-\mathrm{KCl}$ eutectic salt", paper presented at the $31^{\text {st }}$ Symposium on Molten Salt Chemistry, 11-12 November 1999, Sendai, Japan.

4. F. Kobayashi et al. "Dissolution of metal nitrides in $\mathrm{LiCl}-\mathrm{KCl}$ eutectic melts", Proceedings of the International Conference on Future Nuclear Systems Global'99, 29 August-3 September 1999, Jackson Hole, Wyoming.

5. Y. I. Chang and C. E. Till. In LMR: A Decade of LMR Progress and Promise, pp. 129-137, American Nuclear Society, La Grange Park, IL (1990).

6. O. V. Skiba, Yu. P. Savochkin, A. V. Bychkov, P. T. Porodnov, L. G. Babikov, S. K. Vavilov. "Technology of pyrochemical processing and production of nuclear fuel", Proceedings of the International Conference on Future Nuclear Systems Global' 93, 12-17 September 1993, Seattle, Washington.

7. C. C. McPheeters, R. D. Pierce, D. S. Poa, P. S. Maiya. "Pyrochemical methods for actinide recovery from LWR spent fuel", Proceedings of the International Conference on Future Nuclear Systems Global'93, 12-17 September 1993, Seattle, Washington.

8. T. Ogawa, Y. Okamoto, R. J. M. Konings. In Innovative Materials in Advanced Energy Technologies, P. Vincenzini (Ed.), pp. 381-392, Techna Srl. (1999).

9. R. D. Shannon. Acta Cryst. A32, 751-767 (1976).

10. K-G. Chang, X-P. Lu, F-Y. Du, M.-S. Zhao. Chin. J. Chem. 12, 509-515 (1994).

11. K. Serrano and P. Taxil. J. Appl. Electrochem. 29, 497-503 (1999).

12. O. Shirai, T. Iwai, Y. Suzuki, Y. Sakamura, H. Tanaka. J. Alloys Comp. 271-273, 685-688 (1998).

13. D. A. Nissen. J. Inorg. Nucl. Chem. 28, 1740-1743 (1966).

14. D. K. Gosser, Jr. In Modern Techniques in Electroanalysis, P. Vanysek (Ed.), Ch. 7, Wiley, New York (1996).

15. G. M. Cambell and J. A. Leary. "Thermodynamic properties of Pu compounds from EMF measurements", Los Alamos Scientific Laboratory Report LA-3399 (1965).

16. Y. Sakamura, T. Hijikata, K. Kinoshita, T. Inoue, T. S. Storvick, C. L. Krueger, J. J. Roy, D. L. Grimmett, S. P. Fusselman, R. L. Gay. J. Alloys Comp. 271-273, 592-596 (1998).

17. H.-J. Seifert, H. Fink, J. Uebach, "Properties of double chlorides in the systems $\mathrm{ACl} / \mathrm{NdCl} 3$ (A: Na-Cs)", J. Thermal Analysis 33, 625-632 (1988).

18. H.-J. Seifert, J. Sandrock, G. Thiel. J. Therm. Anal. 31, 1309-1318 (1986).

19. M. Gaune-Escard, A. Bogacz, L. Rycerz, W. Szczepaniak. "Enthalpies of formation of liquid $\mathrm{NdCl} 3-\mathrm{KCl}$ mixtures", paper presented at International Symposium on Calorimetry and Chemical Thermodynamics, 23-28 June 1991, Moscow.

20. B. R. Harder, G. Long, W. P. Stanaway. Nuclear Metallurgy 15, 405-432 (1969).

21. R. Molina. Bull. Soc. Chim. Fr. 6, 1184-1190 (1961).

22. P. Chiotti, M. C. Jha, M. J. Tschetter. J. Less-Common Met. 42, 141-161 (1975).

23. L. Martinot and J. Fuger. J. Less-Common Met. 120, 255-266 (1986).

24. G. Picard, F. Seon, B. Tremillion. J. Electroanal. Chem. 102, 65-75 (1979). 
25. V. L. Cherginets. Electrochim. Acta 42, 23-24 (1997).

26. Y. Kanzaki and M. Takahashi. Electroanal. Chem. Interfacial Electrochem. 58, 339-348 (1975).

27. T. Ogawa. "Thermodynamic model of Li2O behavior in LiCl-KCl eutectic melt", paper presented at the $31^{\text {st }}$ Symposium on Molten Salt Chemistry, 11-12 November 1999, Sendai, Japan.

28. R. Combes, M-N. Levelut, B. Tremillion. J. Electroanal. Chem. 91, 125-131 (1978).

29. O. Shirai, T. Iwamoto, Y. Arai. Personal communication.

30. T. Higashi and K. Minato. Paper to be presented at the $8^{\text {th }}$ Japan-China Bilateral Conference on Molten Salt Chemistry and Technology, 29 Oct.-1 Nov., Kitakyuushuu, Japan. 